\title{
An ultra-sensitive electrochemical sensor of Ni/Fe-LDH toward nitrobenzene with the assistance of surface functionalization engineering
}

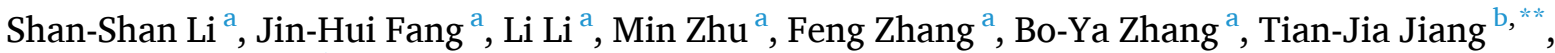 \\ Yong-Xing Zhang ${ }^{\text {a," }}$ \\ ${ }^{a}$ Anhui Province Key Laboratory of Pollutant Sensitive Materials and Environmental Remediation, Department of materials science and engineering, Huaibei Normal \\ University, Huaibei, 235000, PR China \\ ${ }^{\mathrm{b}}$ CAS Key Laboratory of Coastal Environmental Processes and Ecological Remediation and Shandong Key Laboratory of Coastal Environmental Processes, Yantai \\ Institute of Coastal Zone Research (YIC), Chinese Academy of Sciences (CAS), Yantai, Shandong, 264003, PR China
}

\section{A R T I C L E I N F O}

\section{Keywords:}

$\mathrm{Ni} /$ Fe layered double hydroxides

Sodium dodecylsulfate

Surface functionalization engineering

Nitrobenzene

Electroanalysis

\begin{abstract}
A B S T R A C T
Hypersensitive detection of organic pollutions with high toxicity in drinking water always keeps its challenge in electroanalysis due to their low concentration and electrochemical redox inert. In this work, a novel nanomaterial modified electrode for the sensitive detection of nitrobenzene (NB) is presented, based on environmental friendly and cost-effective $\mathrm{Ni} / \mathrm{Fe}$ layered double hydroxides functionalized with sodium dodecyl sulfate (Ni/Fe(SDS)-LDH). Such 2D layered composites were prepared and used to improve the sensitivity for NB detection, due to its good catalytic activity for NB reduction. Besides, the proposed electrode shows a remarkably promoted sensitivity to NB compared to $\mathrm{Ni} / \mathrm{Fe}-\mathrm{LDH}$ modified one. It is because that the surface modifier SDS can provide more adsorption sites to significantly improve the adsorption of NB, which has been confirmed by the adsorption experiment and the characterization of Fourier transform infrared spectroscopy (FTIR). As a result, an impressive sensing behaviour is achieved at the proposed $\mathrm{Ni} / \mathrm{Fe}(\mathrm{SDS})$-LDHs modified electrode with a sensitivity

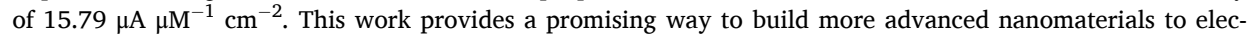
trochemical detection of organic pollution based on energetically synergizing of adsorption by surface functionalization engineering.
\end{abstract}

\section{Introduction}

The environmental pollution in drinking water caused by the discharge of industrial waste is serious. Among the pollutions, nitroaromatic compounds are very harmful to human health [1-3]. They have been classified as highly toxic carcinogens, which remain their carcinogenic activities even at trace level, especially nitrobenzene (NB) $[4,5]$. NB is a popular product in agricultural chemicals, dyes and explosive industries, and has been considered as one of priority strictly controlled pollutions by many countries [6-9]. After being ingested, NB may cause many disorders in human body, e.g. respiratory failure [10, 11]. Therefore, the sensitive detection of NB is extremely important from eco-toxicological point of view.

At present, various analytical methods have been used to detect NB, such as optical sensor [12,13], gas chromatography [14], high-performance liquid chromatography (HPLC) [15] and so on [16].
However, compared with the above traditional methods, the electrochemical analysis has its impressive advantages, e.g. low cost, easy to operation, rapidity and feasibility for field analysis [17-20]. Otherwise, the development of nanomaterials with excellent properties further brings a new prospect for the electroanalysis of NB. Although a great amount of nanomaterials have been proposed for the sensitive detection of $\mathrm{NB}$, in many cases, the electrochemical performances of nanomaterials are based on the good catalytic activity of noble metal $[8,10$, 21-24]. It can be explained by the fact that NB is notoriously chemical insert for reduction on electrode [25], since $-\mathrm{NO}_{2}$ group on benzene ring needs four electrons for the reduction to $-\mathrm{NHOH}$, and six electrons for the reduction to $-\mathrm{NH}_{2}$ [10]. The multiple electron capture process results in its relatively difficult reduction. Considering the high cost of noble-metal, exploring the cost-effective and noble-metal-free nanomaterials with active catalytic activity for the sensitive electroanalysis of NB remains its emergency demanding task and still a challenge in

\footnotetext{
* Corresponding author.

** Corresponding author.

E-mail addresses: tjjiang@yic.ac.cn (T.-J. Jiang), zyx07157@mail.ustc.edu.cn (Y.-X. Zhang).
} 


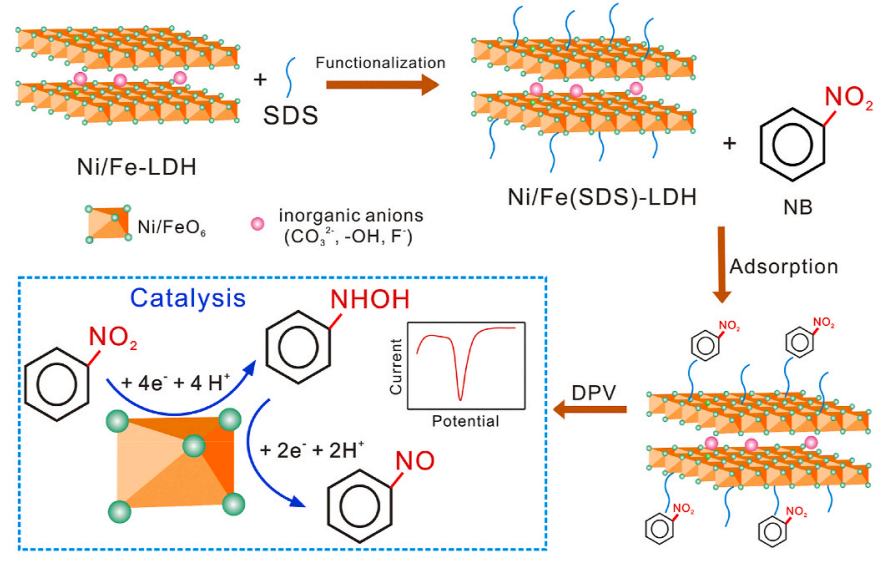

Scheme 1. Fabrication of Ni/Fe(SDS)-LDH and the strategy for NB detection based on synergistic effect of enhanced adsorption and electrocatalysis on $\mathrm{Ni}$ / Fe-LDH functionalized with SDS.

electroanalysis field.

In addition to the catalytic activities of nanomaterials, it has been found that their adsorption abilities also play a key role in the improvement of electrochemical performance towards pollution. In this case, the analyte (i.e. NB) can be adsorbed from the homogeneous solution by nanomaterials and accumulated on the electrode surface, where the electrochemical reaction occurs subsequently and giving the electrochemical signal [26]. Considering the importance of both adsorption capacity and catalytic activity, the nanomaterials with good adsorption and catalytic properties are expected to be used as the electrode modifier for the highly sensitive detection of NB.

Layered double hydroxides (LDHs) are really famous for their intrinsic catalytic activity and amazing adsorption property [27-31]. Various transition metals with mixed valence have been introduced to the formation of the LDH, for instance, Ni/Co-LDH [32,33], Ni/Fe-LDH [34-36], Co/Fe-LDH [37-39], which may bring a great potential to enhance the catalytic activities of LDHs [40]. Actually, it has been reported that multi-metal LDH has a good catalytic performance for the reduction of organic matter, such as metronidazole and 2-nitrophenol [41]. Utilizing this catalytic activity, the LDH is a promising candidate for the electroanalysis of NB. Additionally, LDHs also exhibit good adsorption property to a variety of inorganic pollution, especially anionic species (i.e., $\mathrm{As}(\mathrm{III})$ and $\mathrm{Cr}(\mathrm{VI})$ ) $[42,43]$. The inorganic anions $\left(\mathrm{CO}_{3}^{2-}, \mathrm{OH}^{-}, \mathrm{F}^{-}\right.$, etc. $)$in the interlayer spacing of $\mathrm{LDH}$ materials can exchange with the anionic pollution and thus enhance the adsorption. However, the adsorption abilities of LDHs materials toward organic matter are relatively poor. It is because that the organic matter (i.e. NB) shows a hydrophobic properties, while LDH is opposite hydrophilic. As a result, the adsorption of LDH towards NB is limited, which will further hinder their application in detection NB. To overcome this bottleneck, it is very promising to extend such materials to adsorb organic pollution by the surface functionalization with organic anions. Sodium dodecyl sulfate (SDS) has been extensively applied as the anionic group to modify and functionalize LDH, by which the adsorption ability of LDH can be adjusted by SDS with its hydrophobic affinity [44,45]. Ruan et al. demonstrated that the Ca/Al-SDS-LDHs appeared to have an enhanced adsorption ability toward nitrobenzene in water compared with $\mathrm{Ca} / \mathrm{Al}-\mathrm{Cl}-\mathrm{LDH}$ without SDS [45]. You et al. also suggested the $\mathrm{Mg} / \mathrm{Al}$-SDS-LDH had a positive effect for the sorption of organic compounds [46]. Therefore, the combination of SDS and $\mathrm{Ni} / \mathrm{Fe}-\mathrm{LDH}$ materials may provide an appealing way to increase the adsorption ability towards NB and thus improve detection performance.

In this work, we fabricated the $\mathrm{Ni} / \mathrm{Fe}(\mathrm{SDS})-\mathrm{LDH}$, which use SDS as the surface functional anion, to modify the bare glass carbon electrode
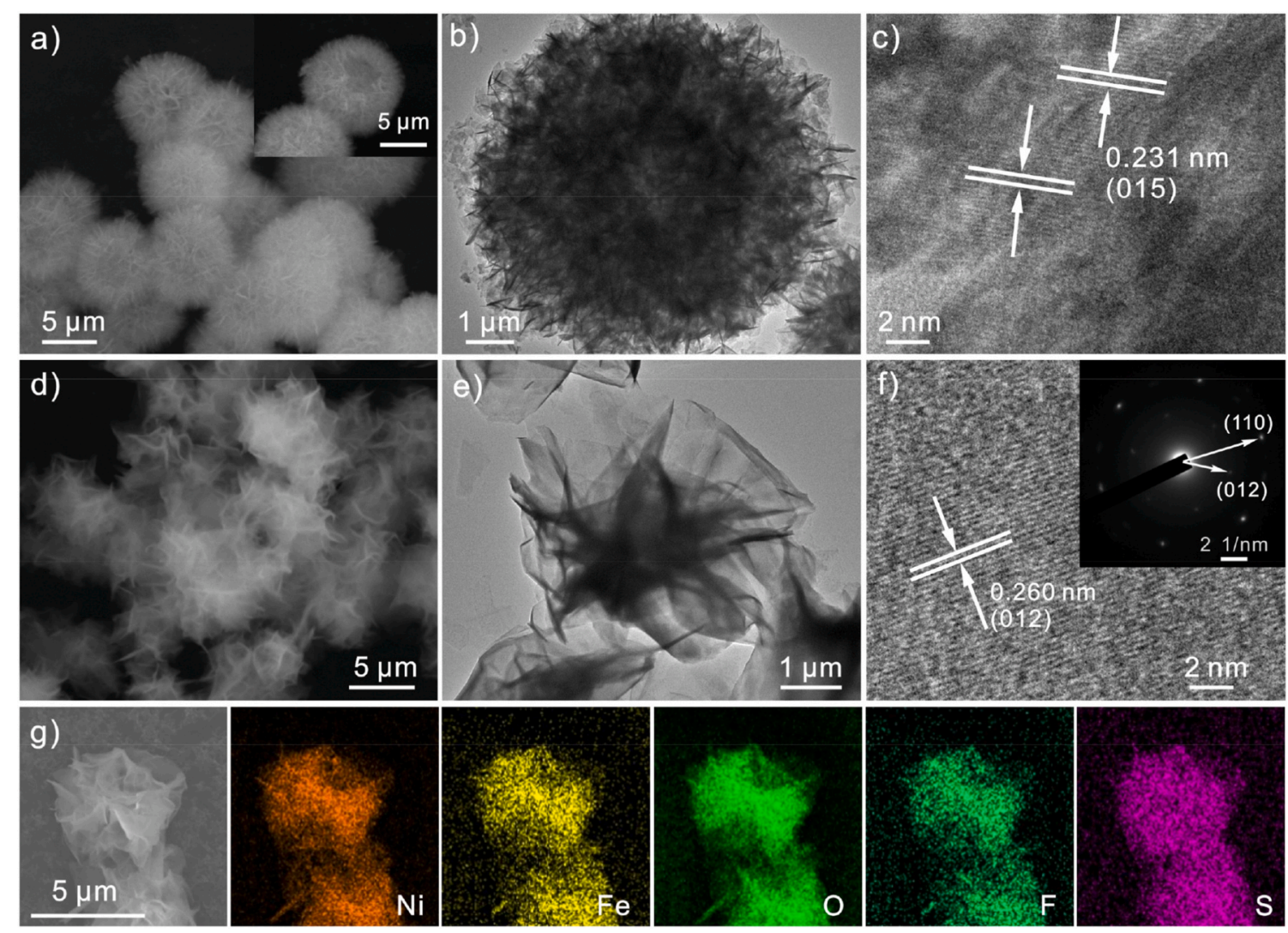

Fig. 1. a) SEM, b) TEM and c) HRTEM images of the Ni/Fe-LDH. d) SEM, e) TEM, f) HRTEM images and g) Elemental mapping of as-synthesized Ni/Fe(150 mg SDS)LDH. Insets in $f$ is the corresponding SAED. 

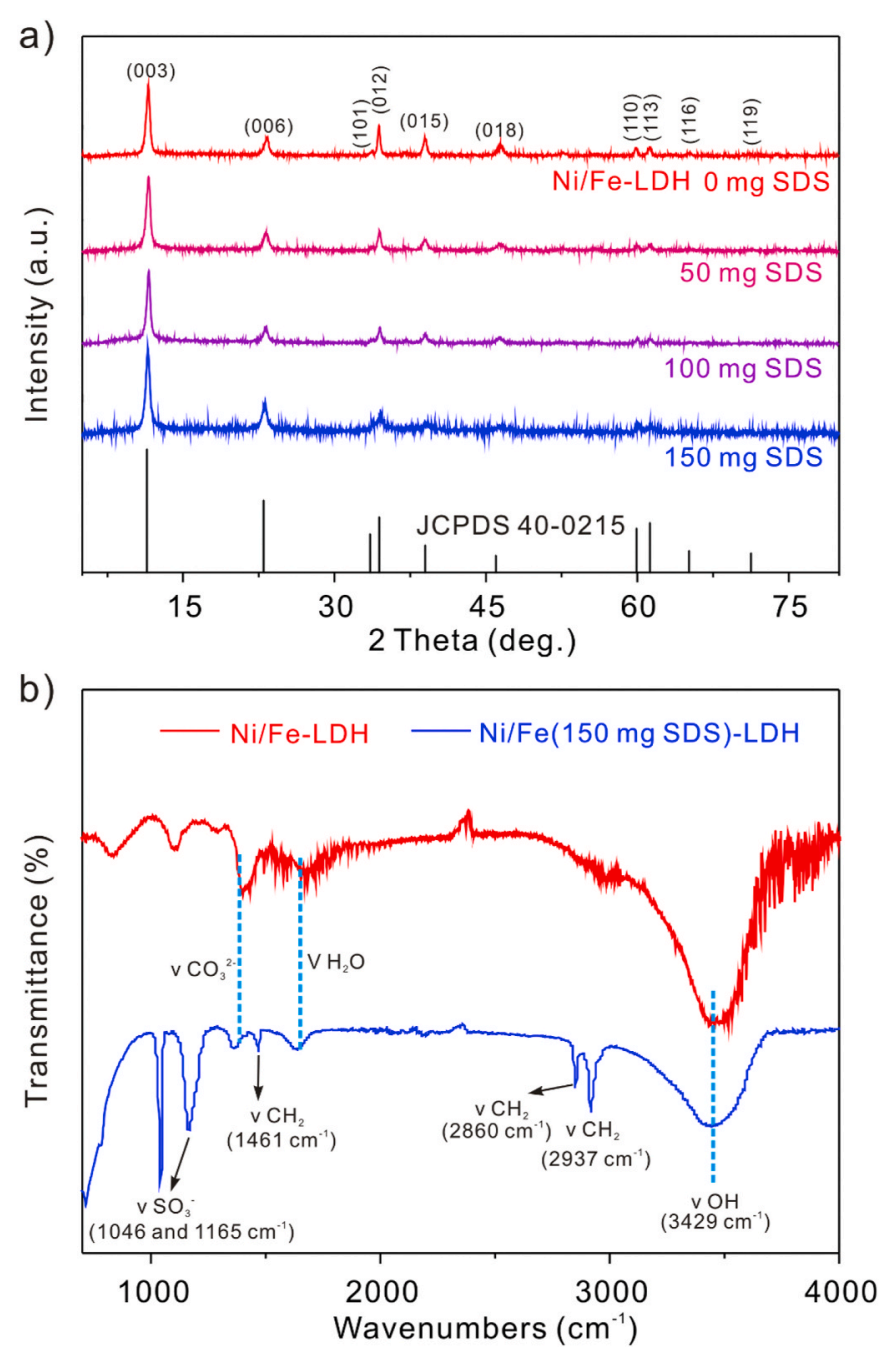

Fig. 2. a) XRD patterns of the $\mathrm{Ni} / \mathrm{Fe}(\mathrm{SDS})-\mathrm{LDH}$ with the various content of SDS from 0 to $150 \mathrm{mg}$. b) FTIR spectra of Ni/Fe-LDH and Ni/Fe(150 mg SDS)-LDH.

(GCE) for the electroanalysis of NB. For comparison, the Ni/Fe-LDHs with different content of SDS are prepared, and the effect of the content of SDS on their structure, adsorption ability and electrochemical behaviors are further comprehensively investigated. In detailed, a series of characterizations are performed to give a clear understanding on the structure of $\mathrm{Ni} / \mathrm{Fe}(\mathrm{SDS})-\mathrm{LDH}$ and $\mathrm{Ni} / \mathrm{Fe}-\mathrm{LDH}$, including scanning electron microscopy (SEM), transmission electron microscopy (TEM), Fourier transform infrared spectroscopy (FTIR) and X-ray photoelectron spectroscopy (XPS). With the assistance of surface functionalization engineering by SDS, the $\mathrm{Ni} / \mathrm{Fe}(\mathrm{SDS})-\mathrm{LDH}$ has a remarkably much improved sensing behavior than that of $\mathrm{Ni} / \mathrm{Fe}-\mathrm{LDH}$, well proving attractivity of the proposed strategy. Moreover, the stability, the interference and the detection accuracy in practical analysis on $\mathrm{Ni} / \mathrm{Fe}(\mathrm{SDS})-$ LDH GCE are evaluated with good results.

\section{Experiment section}

\subsection{Chemical reagents}

The needed reagents for the preparing of $\mathrm{Ni} / \mathrm{Fe}(\mathrm{SDS})-\mathrm{LDH}$ are $\mathrm{NiCl}_{2} \bullet 6 \mathrm{H}_{2} \mathrm{O}, \mathrm{FeCl}_{3} \bullet 6 \mathrm{H}_{2} \mathrm{O}, \mathrm{CON}_{2} \mathrm{H}_{4}, \mathrm{NH}_{4} \mathrm{~F}$ and SDS. The buffer solution of electrochemical detection are $\mathrm{Na}_{2} \mathrm{HPO}_{4}, \mathrm{NaH}_{2} \mathrm{PO}_{4}, \mathrm{CH}_{3} \mathrm{COONa}$, $\mathrm{CH}_{3} \mathrm{COOH}, \mathrm{KCl}, \mathrm{K}_{3}\left[\mathrm{Fe}(\mathrm{CN})_{6}\right]$ and $\mathrm{K}_{4}\left[\mathrm{Fe}(\mathrm{CN})_{6}\right]$. All these reagents and the NB used in this work were purchased from Sinopharm Chemical Reagent Co., Ltd., Shanghai, China. The reagents were used without further purification. The deionized (DI) water was purified to meet $>18.2 \mathrm{M} \Omega \mathrm{cm}$.

\subsection{Synthesis of $\mathrm{Ni} / \mathrm{Fe}(\mathrm{SDS})-\mathrm{LDH}$ and $\mathrm{Ni} / \mathrm{Fe}-\mathrm{LDH}$}

The synthesis of $\mathrm{Ni} / \mathrm{Fe}(\mathrm{SDS})-\mathrm{LDH}$ is operated as following: 1.125 mmol NiCl${ }_{2} \bullet 6 \mathrm{H}_{2} \mathrm{O}$ and $0.375 \mathrm{mmol} \mathrm{FeCl}_{3} \bullet 6 \mathrm{H}_{2} \mathrm{O}$ were added into $30 \mathrm{~mL}$ deionized water, and then stirred to forming a clear solution. $0.3 \mathrm{~g}$ $\mathrm{CON}_{2} \mathrm{H}_{4}, 0.2222 \mathrm{~g} \mathrm{NH}_{4} \mathrm{~F}$ and different content of SDS (50, 100, 150, 200 $\mathrm{mg}$ ) were added into above solution and continued to stirring for $4 \mathrm{~h}$. After that, the resulting solution was transferred into a $50 \mathrm{~mL}$ Teflonlined autoclave and kept it at $160{ }^{\circ} \mathrm{C}$ for $4 \mathrm{~h}$. The final product of $\mathrm{Ni}$ / $\mathrm{Fe}(\mathrm{SDS})$-LDH was obtained with thoroughly washing and drying. For the preparation of $\mathrm{Ni} / \mathrm{Fe}-\mathrm{LDH}$, the process is similar with $\mathrm{Ni} / \mathrm{Fe}(\mathrm{SDS})$ $\mathrm{LDH}$, but without the addition of SDS.

\subsection{Characterization}

The as-synthesized $\mathrm{Ni} / \mathrm{Fe}(\mathrm{SDS})-\mathrm{LDH}$ and $\mathrm{Ni} / \mathrm{Fe}-\mathrm{LDH}$ were characterized by SEM (JEOL JSM-6610LV) equipped with X-ray energy dispersive spectroscopy (EDS), TEM (JEOL JEM-2100), X-ray diffraction (XRD, Panalytical Empyrean diffractometer) with $\mathrm{Cu} \mathrm{K} \alpha$ radiation (1.5418 ̊), FTIR (Nicolet 6700), XPS (VGESCA-LABMKIIX) and Auto Fast Specific Surface Area Analyzer (Brunauer-Emmett-Teller (BET), Tristar II 3020 M). The HPLC was carried out by LC-20AD of Shimadzu.

\subsection{Electrochemical measurements}

All the electrochemical measurements were performed on electrochemical workstation (CHI-760E, ChenHua Instruments Co., Shanghai, China) with traditional three-electrode system that GCE with $3 \mathrm{~mm}$ diameter and Pt wire serve as working electrode and counter electrode, respectively. Besides, all potential values given in this work refer to $\mathrm{Ag}$ / $\mathrm{AgCl}$ reference electrode. The electrochemical detection method is the differential pulse voltammetry (DPV) with the following parameters: amplitude, $25 \mathrm{mV}$; increment potential, $4 \mathrm{mV}$. The cyclic voltammetry (CV) and electrochemical impedance spectroscopy (EIS) are measured in a solution containing of $5 \mathrm{mM} \mathrm{K}_{3} \mathrm{Fe}(\mathrm{CN})_{6}$ and $0.1 \mathrm{M} \mathrm{KCl}$.

The modification of the electrode with $\mathrm{LDH}$ is using the traditional drop-coating method. Firstly, $8 \mathrm{mg} \mathrm{LDH}$ was dissolved in $2 \mathrm{~mL}$ of water to form a homogeneous suspension with sufficient sonication. Then, a 5 $\mu \mathrm{L}$ suspension was dripped on the fresh polished GCE and the electrode was dried naturally at room temperature for further using.

\subsection{Adsorption experiments}

The adsorption abilities of Ni/Fe(SDS)-LDHs with various SDS (0, 50, $100,150 \mathrm{mg}$ ) content were studied as following: $10 \mathrm{mg} \mathrm{Ni} / \mathrm{Fe}(0-150 \mathrm{mg}$ SDS)-LDHs was well dispersed in $10 \mathrm{~mL} 0.1 \mathrm{M}$ phosphate buffer solution ( $\mathrm{PBS}, \mathrm{pH}=7$ ), which is consistent with electrochemical detection condition. Then the different concentrations of NB $(0-400 \mu \mathrm{M})$ were added in the above solution forming homogeneous mixture. After the mixture stirring at room temperature for $24 \mathrm{~h}$, the adsorbent was separated from aqueous solution by centrifugation. Herein, the concentrations of $\mathrm{NB}$ were quantified with maximum adsorption wavelength of $268 \mathrm{~nm}$ by an UV-Vis spectrophotometer (N6000, YuKe Instrument Co., Shanghai, China).

\section{Result and discussion}

\subsection{Strategy for the detection}

As shown in Scheme 1, during the preparation of $\mathrm{LDH}$, the added SDS is used as a surfactant to functionalize the surface of $\mathrm{Ni} / \mathrm{Fe}-\mathrm{LDH}$. A large number of hydroxyl groups on the surface of $\mathrm{Ni} / \mathrm{Fe}-\mathrm{LDH}$ are effectively combined with the sulfonic acid groups of SDS through electrostatic 



Fig. 3. a) XPS full spectra and the high-resolution spectra of b) O 1s, c) C 1s and S 2p, d) Fe 2p and Ni 2p of Ni/Fe-LDH and Ni/Fe(150 mg SDS)-LDH.

attraction. The hydrophobic end of SDS molecular chain is exposed, thereby changing the hydrophilic properties of Ni/Fe-LDH. With the hydrophobic affinity between SDS and NB, the resulting Ni/Fe(SDS)LDH has an enhanced adsorption ability toward NB. A large amount of $\mathrm{NB}$ can be adsorbed on Ni/Fe(SDS)-LDH. Furthermore, with the help of the electrocatalysis of $\mathrm{Ni} / \mathrm{FeO}_{6}$ in $\mathrm{Ni} / \mathrm{Fe}$ (SDS)-LDH, the adsorbed $\mathrm{NB}$ will be effectively reduced to phenylhydroxylamine and nitrosobenzene with four-electron and two-electron transfer, respectively [21]. It is known that the reduction of NB to phenylhydroxylamine is an irreversible process, while the phenylhydroxylamine and nitrosobenzene are the well-defined redox couple [47]. Three peaks are all identified in CV, but only one peak appears using DPV, which was used as the detection signal of NB. An excellent electrochemical performance is achieved based on the synergistic effect of adsorption and electrocatalysis on $\mathrm{Ni} / \mathrm{Fe}$ (SDS)-LDH. More details will be discussed later.

\subsection{Characterization of $\mathrm{Ni} / \mathrm{Fe}(S D S)-L D H$}

Fig. 1 illustrates the SEM and TEM images of pristine Ni/Fe-LDH and $\mathrm{Ni} / \mathrm{Fe}(150 \mathrm{mg}$ SDS)-LDH. The Ni/Fe-LDH without SDS shows typical hollow sphere with a particle size of about $6 \mu \mathrm{m}$, composed of many hierarchically structured sheets in detail (Fig. 1a and b). This uniform hollow hierarchical structure is good for the enhancement of specific surface area. The lattice spacing of $0.231 \mathrm{~nm}$ presented in Fig. 1c is perfectly corresponding to the (015) plane in $\mathrm{Ni}_{0.75} \mathrm{Fe}_{0.25}(-$ $\left.\mathrm{CO}_{3}\right)_{0.125}(\mathrm{OH})_{2}$. Apparently, $\mathrm{Ni} / \mathrm{Fe}(\mathrm{SDS})-\mathrm{LDH}$ exhibits a rather different appearance after the addition of $150 \mathrm{mg}$ SDS in Ni/Fe-LDH (Fig. 1d and e). The structure of $\mathrm{Ni} / \mathrm{Fe}(150 \mathrm{mg}$ SDS)-LDH shows typical thin nanosheets rather than sphere. For details, the effect of SDS amounts on the morphology of Ni/Fe-LDH is also studied. As shown in Fig. S1 (in Supplementary Materials), with the increasing of SDS concentration (0-150 $\mathrm{mg}$ ), the morphology of Ni/Fe-LDH gradually change from spherical-like structure to dispersed transparent and flocculent nanosheets, which well prove that the introduction of SDS could functionalize the surface of $\mathrm{Ni}$ / Fe-LDH hollow sphere.

Furthermore, the XRD patterns of Ni/Fe(SDS)-LDH with SDS content from 0 to $150 \mathrm{mg}$ are recorded. Although the significant differences can be observed between the morphologies of $\mathrm{Ni} / \mathrm{Fe}(50,100,150 \mathrm{mg}$ SDS)$\mathrm{LDH}$ and $\mathrm{Ni} / \mathrm{Fe}-\mathrm{LDH}$, their XRD patterns (Fig. 2a) can all well index to the XRD pattern of $\mathrm{Ni}_{0.75} \mathrm{Fe}_{0.25}\left(\mathrm{CO}_{3}\right)_{0.125}(\mathrm{OH})_{2} \cdot 0.38 \mathrm{H}_{2} \mathrm{O}$ (JCPDS No. 40-0215) [48]. It suggests the addition of $0-150 \mathrm{mg}$ SDS is unable to change the structure of $\mathrm{Ni} / \mathrm{Fe}(\mathrm{SDS})-\mathrm{LDH}$, but only slightly affect the crystallization which resulted in the decrease of diffraction peaks intensity. The lattice spacing at $0.260 \mathrm{~nm}$ and the selected area electron diffraction (SAED) in Fig. If all confirm the crystal face of Ni/Fe(150 mg SDS)-LDH. As illustrated in Fig. $1 \mathrm{~g}$ and Fig. S1e, the uniform distributions of $\mathrm{Ni}, \mathrm{Fe}, \mathrm{O}$ and $\mathrm{F}$ are observed on $\mathrm{Ni} / \mathrm{Fe}(150 \mathrm{mg}$ SDS)-LDH and $\mathrm{Ni} / \mathrm{Fe}-\mathrm{LDH}$, while additional existence of $\mathrm{S}$ is found in the elemental maps of Ni/Fe(150 mg SDS)-LDH nanosheets, which belongs to SDS. The different content of $S$ are determined to identify the real loading amount of SDS into Ni/Fe(SDS)-LDH by EDS (Fig. S2). It is clearly that the atomic ratio of $\mathrm{S} /(\mathrm{Fe}+\mathrm{Ni})(9.87,20.75,27.93 \%$ for $50,100,150 \mathrm{mg}$ SDS, respectively) are generally grows as the increase of SDS, well proving that the added SDS during the prepartion process are effectively coated on the surface of $\mathrm{Ni} / \mathrm{Fe}(\mathrm{SDS})-\mathrm{LDH}$. The appearance of some new vibration peaks in FTIR spectra of Ni/Fe(150 mg SDS)-LDH compared with $\mathrm{Ni} / \mathrm{Fe}-\mathrm{LDH}$ further reveals the presence of SDS (Fig. 2b), such as the peaks at 2860 and $2937 \mathrm{~cm}^{-1}$ referring to the $-\mathrm{CH}_{2}$ groups [49], the bands at 1046 and $1165 \mathrm{~cm}^{-1}$ ascribing to the $\mathrm{S}=\mathrm{O}$ bonds of SDS [50]. The other peaks should be attributed to the characteristic vibration of $\mathrm{LDH}$, which have been marked in Fig. $2 \mathrm{~b}$.

It is worth mentioned that more content of SDS (200 mg) added into 

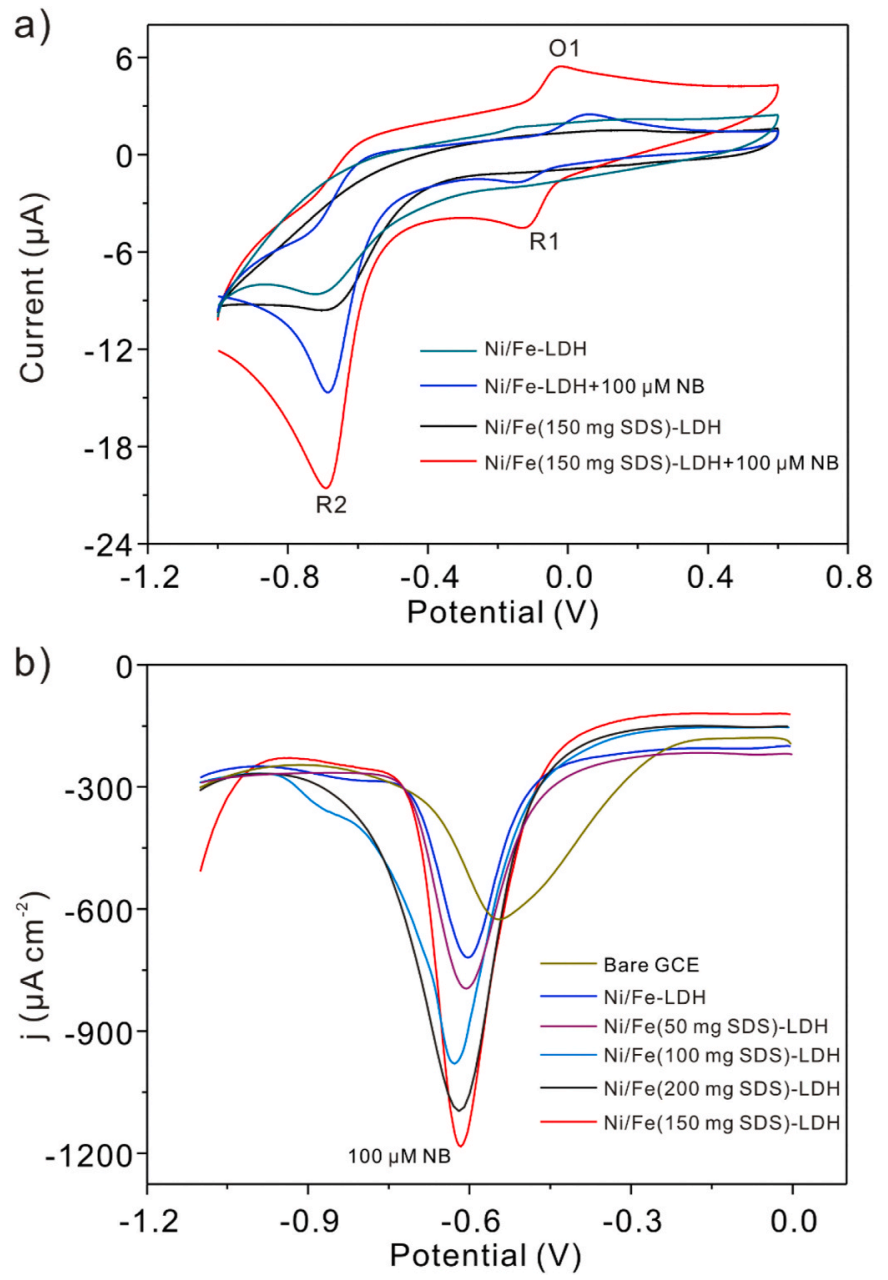

Fig. 4. a) $\mathrm{CV}$ curves of $\mathrm{Ni} / \mathrm{Fe}-\mathrm{LDH}$ and $\mathrm{Ni} / \mathrm{Fe}(150 \mathrm{mg}$ SDS)-LDH modified GCEs in $0.1 \mathrm{M}$ PBS ( $\mathrm{pH}=7.0$ ) without and with $100 \mu \mathrm{M} \mathrm{NB}$, respectively. b) DPV response of bare GCE, Ni/Fe-LDH and Ni/Fe(0-200 mg SDS)-LDH toward 100 $\mu \mathrm{M} N B$ at a scan rate of $0.04 \mathrm{~V} \mathrm{~s}^{-1}$ in $0.1 \mathrm{M}$ PBS $(\mathrm{pH}=7.0)$, respectively.

$\mathrm{Ni} / \mathrm{Fe}-\mathrm{LDH}$ has also been investigated. As shown in Fig. S3a, the SEM of $\mathrm{Ni} / \mathrm{Fe}(200 \mathrm{mg}$ SDS)-LDH also has a typical nanosheet structure. However, the diffraction peaks of $\mathrm{Ni} / \mathrm{Fe}(200 \mathrm{mg}$ SDS)-LDH change remarkably compared with $\mathrm{Ni} / \mathrm{Fe}(0-150 \mathrm{mg}$ SDS $)-\mathrm{LDH}$, indicating the reconstruction of $\mathrm{Ni} / \mathrm{Fe}-\mathrm{LDH}$ in presence of excess SDS [51]. Large amount works have proved that SDS can exchange with the inorganic anions in the interlayer of $\mathrm{LDH}$ (including $\mathrm{CO}_{3}^{2-}, \mathrm{OH}^{-}, \mathrm{F}^{-}$, etc.) and intercalate the interlayer, which can cause clear negative shift of (003) peak at $11.41^{\circ}$ to lower $2 \theta$ like the phenomenon in Fig. S3b [52,53]. The sharp increase of $\mathrm{S} /(\mathrm{Fe}+\mathrm{Ni}$ ) ratio (47.92\%) (Fig. S3c) and obvious color change (Fig. S4f) of Ni/Fe(200 mg SDS)-LDH further give the evidence that the excess SDS $(200 \mathrm{mg}$ ) may partly intercalate into the interlay of $\mathrm{Ni} / \mathrm{Fe}-\mathrm{LDH}$. In fact, LDH intercalated with SDS is possible conductive to enhance the adsorption of NB. However, the hydrophobic property of $\mathrm{Ni} / \mathrm{Fe}(200 \mathrm{mg}$ SDS)-LDH also increase dramatically, resulting in its poor dispersibility in water and even difficult to modify on GCE surface by drop-coating method in our work. The water contact angle test between $\mathrm{Ni} / \mathrm{Fe}(0-200 \mathrm{mg}$ SDS)-LDH also proves our point (Figs. S4a-e). As the increase of SDS, the contact angles increase $\left(15.6,20.1,44.3,72.9^{\circ}\right.$ for $0,50,100,150 \mathrm{mg}$ SDS, respectively) and reach maximum at $200 \mathrm{mg}$ SDS $\left(130.8^{\circ}\right)$. This result is consistent with that found in another works about the SDS intercalated LDH [54,55]. The strong hydrophobic properties of $\mathrm{Ni} / \mathrm{Fe}(200 \mathrm{mg}$ SDS)-LDH not only have an adverse effect on the control of electrode morphology, but also very unfavorable for the electrolyte to be close to electrode surface, which will both lead to decreased electrochemical signal although with excellent adsorption ability $[56,57]$. The poor detection performance of $\mathrm{Ni} / \mathrm{Fe}(200 \mathrm{mg}$ SDS)-LDH will be discussed below. Therefore, we chose $150 \mathrm{mg}$ as optimal amount of SDS and following discussion is mainly focused on $\mathrm{Ni} / \mathrm{Fe}(150 \mathrm{mg}$ SDS)-LDH.

We compare the XPS spectra of Ni/Fe-LDH and Ni/Fe(150 mg SDS)LDH (Fig. 3) to further understand the changes of binding energy in LDH structure before and after functionalizing with SDS. Besides the emergence of S $2 s$ and S $2 p$ (Fig. 3a), the obvious decrease of the $-\mathrm{OH} / \mathrm{O}_{\text {toal }}$ ratio (Fig. 3b) in $\mathrm{Ni} / \mathrm{Fe}(150 \mathrm{mg}$ SDS)-LDH compared with $\mathrm{Ni} / \mathrm{Fe}-\mathrm{LDH}$ means that the $-\mathrm{OH}$ on $\mathrm{Ni} / \mathrm{Fe}-\mathrm{LDH}$ is combined with $-\mathrm{SO}_{3}^{-}$of SDS. Indeed, the positive shift of $\mathrm{O} 1 \mathrm{~s}$ (Fig. $3 \mathrm{~b}$ ) in Ni/Fe(150 mg SDS)-LDH contrast to that in Ni/Fe-LDH further proves this point. Meanwhile, there is almost no change about the Fe $2 \mathrm{p}$ and $\mathrm{Ni} 2 \mathrm{p}$, suggesting the functionalization of SDS does not affect the structure of octahedral $\mathrm{MO}_{6}$ $(\mathrm{M}=\mathrm{Ni}$ and $\mathrm{Fe})$ in LDH. Furthermore, the BET surface areas of $\mathrm{Ni} / \mathrm{Fe}$ (150 mg SDS)-LDH and Ni/Fe-LDH are investigated in Fig. S5. With the addition of SDS, the surface area of $\mathrm{Ni} / \mathrm{Fe}(150 \mathrm{mg}$ SDS)-LDH decreases a lot $\left(9.83 \mathrm{~m}^{2} / \mathrm{g}\right)$ compared with Ni/Fe-LDH $\left(40.25 \mathrm{~m}^{2} / \mathrm{g}\right)$. This is possibly due to the large change in morphology. The original hollow spherical $\mathrm{Ni} / \mathrm{Fe}$-LDH with a large surface area has become nanosheet with smaller surface area. It is worth noting that in previous works, a consensus was reached on the pursuit for large specific surface area to improve the adsorption capacity of nanomaterial. However, herein, Ni/Fe(SDS)-LDH with smaller surface area has better adsorption capacity to NB, resulting from more effective hydrophobic adsorption sites (i.e. SDS) on $\mathrm{Ni} / \mathrm{Fe}$ (SDS)-LDH.

\subsection{Electrochemical characterization}

The electrochemical characterization of $\mathrm{CV}$ and electrochemical impedance resistance (EIS) on Ni/Fe-LDH and Ni/Fe(150 mg SDS)-LDH are respectively examined (Fig. S6). After modified with Ni/Fe-LDH and $\mathrm{Ni} / \mathrm{Fe}(150 \mathrm{mg}$ SDS)-LDH, a sharp decrease of CV current and increase of EIS value are shown. It is the evidence that the conductivities of both $\mathrm{LDH}$ are small, especially for $\mathrm{Ni} / \mathrm{Fe}(150 \mathrm{mg}$ SDS)-LDH. It is foreseeable to know that SDS is non-electronic conductor. However, this decreased conductivity has an ignorable impact on NB detection. Prior to detection, the electroanalytical conditions are optimized in Fig. S7. As shown in Fig. S7a, NB has the highest DPV current in phosphate buffer solution (PBS), due to PBS helps its adsorption of NB on Ni/Fe(150 mg SDS)-LDH (proved in below). When the $\mathrm{pH}$ value of PBS gradually increases to 7.0, the reduction current of NB increases accordingly, and the further increases of $\mathrm{pH}$ lead to the decrease of electrochemical signal. It is suggested that the most favorable condition is under neutral $\mathrm{pH}$ (7.0). Furthermore, the effect of $\mathrm{pH}$ value on the reduction peak potential $\left(\mathrm{E}_{\mathrm{pc}}\right)$ of NB is studied in Fig. S8. The peak position changes linearly with $\mathrm{pH}$, $\mathrm{E}_{\mathrm{pc}}=-0.40-0.029 \mathrm{pH}$, suggesting that protons are involved in the reduction process of NB. This is very consistent with Nernst equation, $\mathrm{E}_{\mathrm{pc}}=\mathrm{E}^{\theta}-(0.059 \mathrm{~m} / \mathrm{n}) \mathrm{pH}$, where the $\mathrm{m}$ and $\mathrm{n}$ represent the number of protons ( $\mathrm{m}$ ) and electrons (n) [57]. As shown, the $\mathrm{m} / \mathrm{n}$ in NB reduction is about $1 / 2$, indicating more electrons participate into such a reduction process than protons and electron plays a more important role. The effect of accumulation time on DPV response to $100 \mu \mathrm{M}$ NB is shown in Fig. S7c. The increase in accumulation time is good for adsorbing more $\mathrm{NB}$, but it will reach a saturation value at about $150 \mathrm{~s}$. At last, we chose the optimized condition as following: in $0.1 \mathrm{M} \mathrm{PBS}$ with a $\mathrm{pH}$ value of 7 , and the accumulation time is $150 \mathrm{~s}$.

\subsection{Electrochemical detection of $N B$}

The electrochemical performance of NB on Ni/Fe(150 mg SDS)-LDH GCE are firstly evaluated by CV. For contrast, the $\mathrm{CV}$ response of $\mathrm{Ni} / \mathrm{Fe}-$ LDH GCE to $100 \mu \mathrm{M} \mathrm{NB}$ is also examined (Fig. 4a). There is no redox response on both electrodes in the absence of NB. As injected with 100 $\mu \mathrm{M} \mathrm{NB}$, three prominent redox peaks are captured, including a pair of 

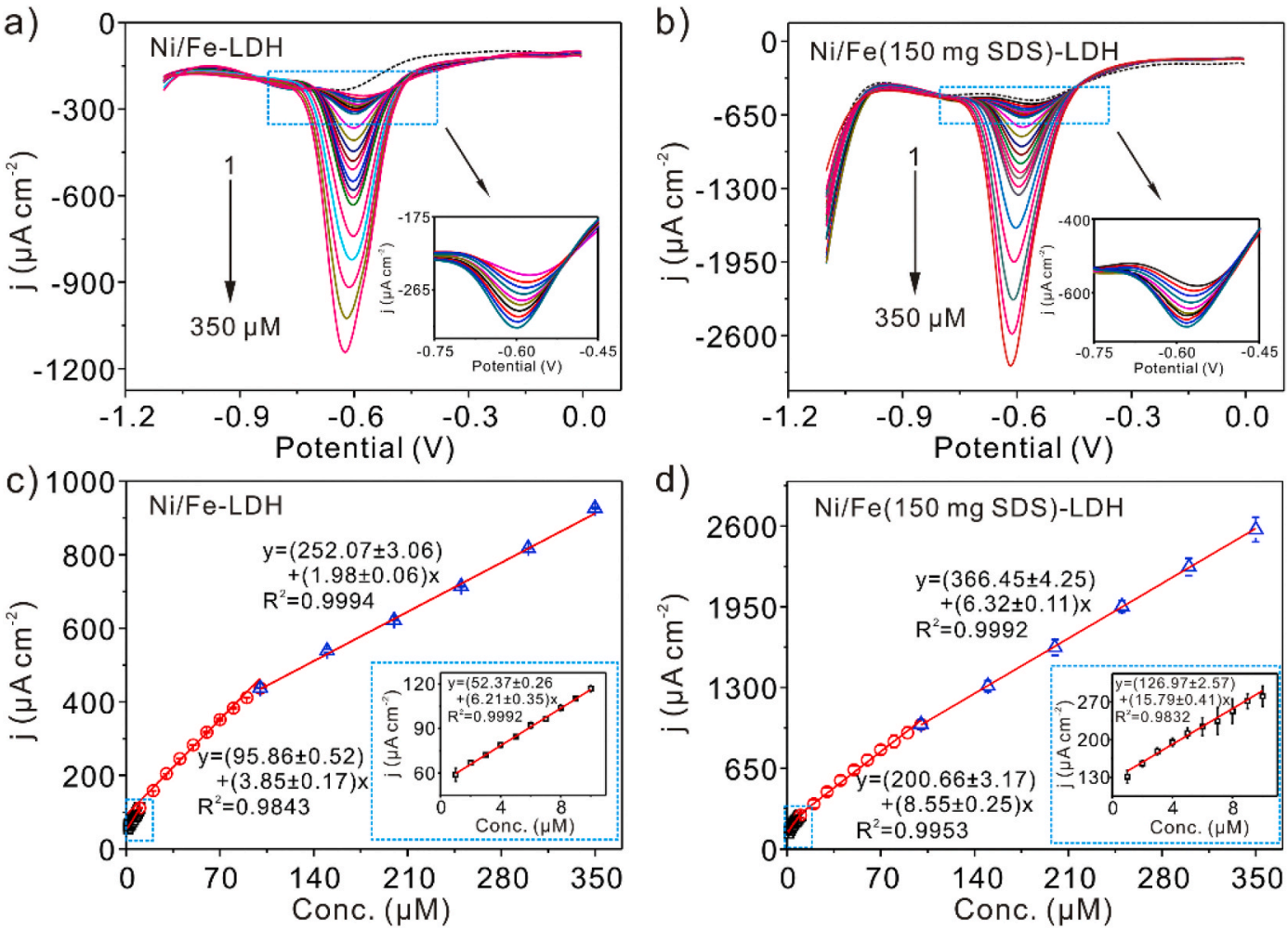

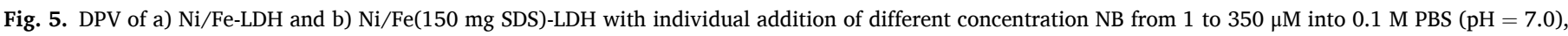

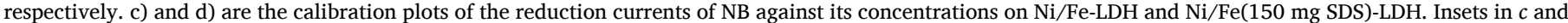
$d$ are partial magnification in low concentration $(1-10 \mu \mathrm{M})$ of NB. The confidence intervals are calculated with a level of $95 \%$.

Table 1

A comparison of electrochemical performance (including linear range, sensitivity and LOD) of electrodes for DPV detection of NB.

\begin{tabular}{|c|c|c|c|c|}
\hline Electrode & $\begin{array}{l}\text { Linear range } \\
(\mu \mathrm{M})\end{array}$ & $\begin{array}{l}\text { Sensitivity }(\mu \mathrm{A} \mu \mathrm{M} \\
\left.-1 \mathrm{~cm}^{-2}\right)\end{array}$ & $\begin{array}{l}\text { LOD } \\
(\mu \mathrm{M})\end{array}$ & Ref. \\
\hline $\begin{array}{l}\text { Pd-polymer-silica } \\
\text { GCE }\end{array}$ & $1-1900$ & 0.371 & 0.06 & [22] \\
\hline$\gamma-\mathrm{Al}_{2} \mathrm{O}_{3} \mathrm{GCE}$ & $0.5-145.5$ & 1.27 & 0.15 & [47] \\
\hline $\begin{array}{l}\text { Au NPs -mesoporous } \\
\text { silica GCE }\end{array}$ & $0.1-2500$ & 0.341 & 0.015 & [21] \\
\hline Au NPs GCE & $0.1-600$ & 1.01 & 0.016 & [10] \\
\hline Co-MOF-MPC & $0.5-15$ & 1780 & 0.21 & [59] \\
\hline $\begin{array}{l}\text { Ag NPs-POSS/RGO } \\
\text { GCE }\end{array}$ & $4-1260$ & - & 0.08 & [60] \\
\hline PAA-Ag NPs GCE & $10-600$ & - & 1.68 & [61] \\
\hline $\mathrm{Ni} / \mathrm{Fe}-\mathrm{LDH}$ & $\begin{array}{l}1-10 \\
10-100 ; \\
100-350\end{array}$ & $\begin{array}{l}6.21 ; \\
3.85 \\
1.98\end{array}$ & 0.327 & $\begin{array}{l}\text { This } \\
\text { work }\end{array}$ \\
\hline $\mathrm{Ni} / \mathrm{Fe}$ (SDS)-LDH & $\begin{array}{l}1-10 \\
10-100 \\
100-350\end{array}$ & $\begin{array}{l}15.79 ; \\
8.55 ; \\
6.32\end{array}$ & 0.093 & $\begin{array}{l}\text { This } \\
\text { work }\end{array}$ \\
\hline
\end{tabular}

NPs: nanoparticles; GCE: glass carbon electrode; Co-MOF-MPC: cobalt-based MOF and macroporous carbon (MPC) composite; RGO: reduced graphene oxide; POSS: polyhedral oligomeric silsesquioxane; PAA: poly(amic) acid.

well-defined redox peaks ( $\mathrm{O} 1$ and $\mathrm{R} 1$ ) and an irreversible reduction peak (R2) on Ni/Fe(150 mg SDS)-LDH GCE. The observed R2 at about -0.70 $\mathrm{V}$ is ascribed to the peak of NB reduction to phenylhydroxylamine with four electron transfer process. Meanwhile, the redox couple of $\mathrm{O} 1$ and $\mathrm{R} 1$ at -0.034 and $-0.12 \mathrm{~V}$ are respectively corresponding to the redox between phenylhydroxylamine and nitrosobenzene with two electron transfer [21,57]. Otherwise, the redox current of $\mathrm{NB}$ on $\mathrm{Ni} / \mathrm{Fe}(150 \mathrm{mg}$ SDS)-LDH is higher than that on Ni/Fe-LDH GCE, giving the evidence of effective NB detection on $\mathrm{Ni} / \mathrm{Fe}(150 \mathrm{mg}$ SDS)-LDH.

The DPV response of Ni/Fe(SDS)-LDHs with various content of SDS

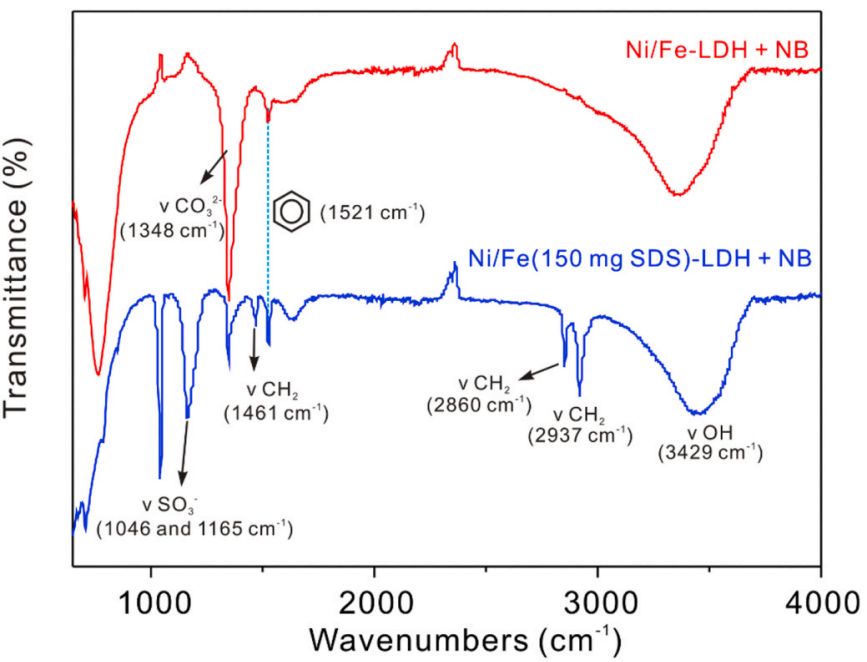

Fig. 6. FTIR spectra of $\mathrm{Ni} / \mathrm{Fe}-\mathrm{LDH}$ and $\mathrm{Ni} / \mathrm{Fe}(150 \mathrm{mg}$ SDS)-LDH with uptake of NB.

have been explored in Fig. 4b. The response current of Ni/Fe(0-150 mg SDS)-LDHs raise steadily with the increase of SDS content. It is because that the modification of SDS is very benefit for the adsorption of NB, which can lead to the improvement of electrochemical signal. However, the current of $\mathrm{Ni} / \mathrm{Fe}(\mathrm{SDS})-\mathrm{LDH}$ with $200 \mathrm{mg}$ SDS becomes lower than that of $150 \mathrm{mg}$. As discussed above, $\mathrm{Ni} / \mathrm{Fe}(200 \mathrm{mg}$ SDS)-LDH cannot be modified uniformly on the surface of GCE due to its high hydrophobicity, and thus leading to a reduced response. For contrast, $\mathrm{Ni} / \mathrm{Fe}(150$ mg SDS)-LDH with both good adsorption properties and waterdispersibility shows the best electroanalytical performance to NB. 

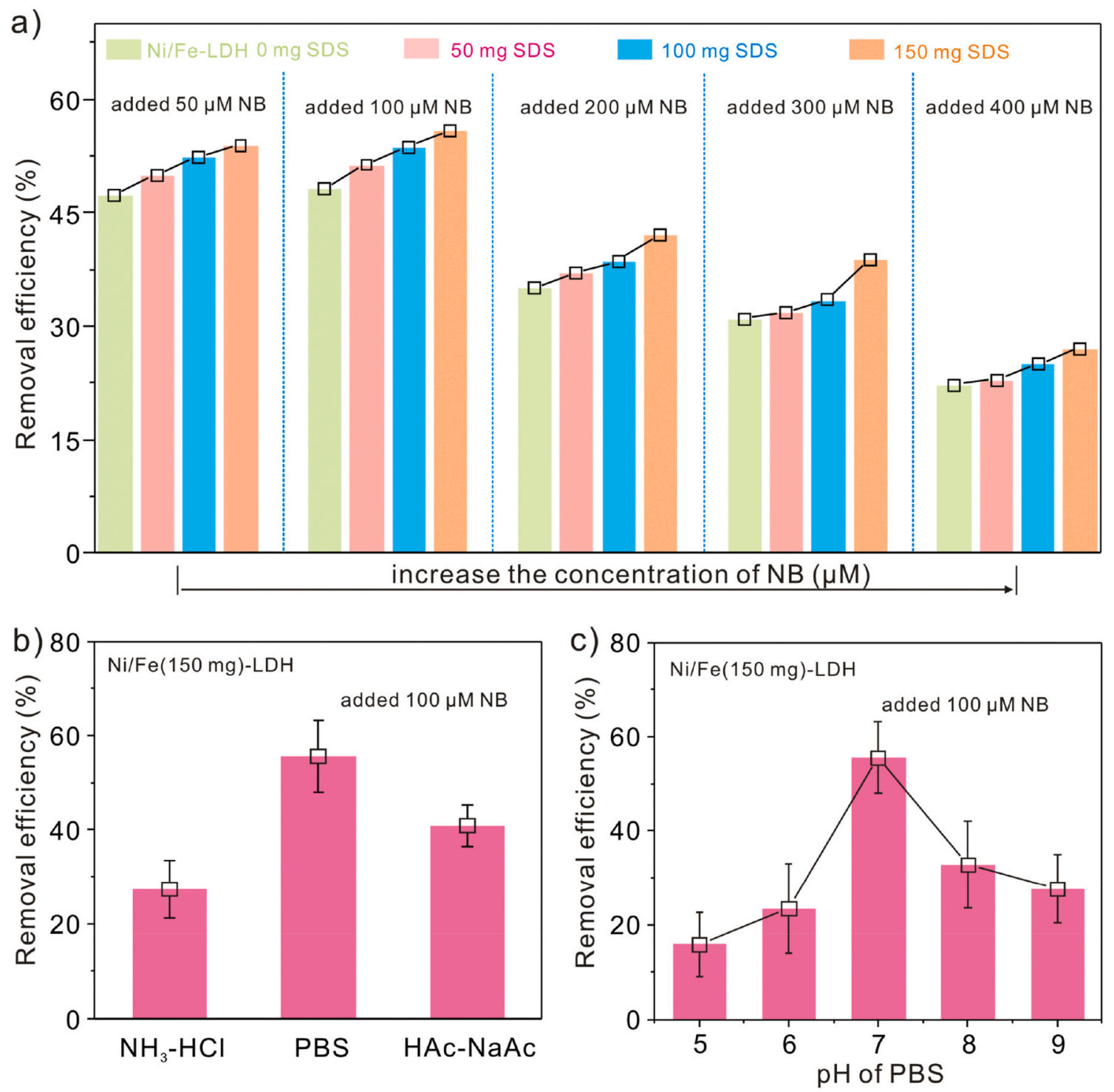

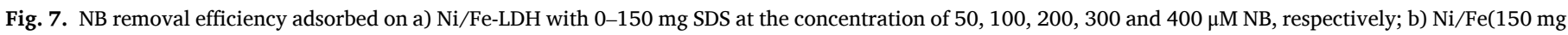
SDS)-LDH with different buffer solution to $100 \mu \mathrm{M} \mathrm{NB}$; c) Ni/Fe(150 mg SDS)-LDH with different pH of $0.1 \mathrm{M}$ PBS to100 $\mu \mathrm{M}$ NB.

We further investigated the DPV electrochemical response of $\mathrm{Ni} / \mathrm{Fe}$ LDH and Ni/Fe(150 mg SDS)-LDH toward NB at different concentrations (Fig. 5), low level (1-10 $\mu \mathrm{M})$, middle concentration $(10-100 \mu \mathrm{M})$ and high level $(100-350 \mu \mathrm{M})$, respectively. Both $\mathrm{Ni} / \mathrm{Fe}-\mathrm{LDH}$ and $\mathrm{Ni} / \mathrm{Fe}(150$ $\mathrm{mg}$ SDS)-LDH modified GCE have well-defined response as the concentration of NB increase (Fig. $5 \mathrm{a}$ and b). The Ni/Fe(150 mg SDS)-LDH GCE has three diverse liner relationships in the concentration range of 1-350 $\mu \mathrm{M}$, expressing as follows:

$\mathrm{j}_{1}\left(\mu \mathrm{A} \mathrm{cm}^{-2}\right)=(15.79 \pm 0.41) \mathrm{C}(\mu \mathrm{M})+(126.97 \pm 2.57)(1-10 \mu \mathrm{M})$. $\mathrm{j}_{2}\left(\mu \mathrm{A} \mathrm{cm}^{-2}\right)=(8.55 \pm 0.25) \mathrm{C}(\mu \mathrm{M})+(200.66 \pm 3.17)(10-100 \mu \mathrm{M})$.

$\mathrm{j}_{3}\left(\mu \mathrm{A} \mathrm{cm}^{-2}\right)=(6.32 \pm 0.11) \mathrm{C}(\mu \mathrm{M})+(366.45 \pm 4.25)(100-350$ $\mu \mathrm{M})$.

The $\mathrm{j}$ is the current density of DPV peak of NB, which is calculated by Current/Area. Area is real electrochemical surface areas (ECSA) of Ni/Fe (150 mg SDS)-LDH GCE, according to the Randles-Sevcik equation, $\mathrm{i}_{\mathrm{p}}=$ $(2.69 \times 105) \mathrm{n}^{3 / 2} \mathrm{ACD}^{1 / 2} \mathrm{v}^{1 / 2}$ in Fig. S9. It is clearly shown that the sensitivities decreases with increased concentration in different concentration range, due to the decreased effect in adsorption enhancement on $\mathrm{Ni} / \mathrm{Fe}(150 \mathrm{mg}$ SDS)-LDH and reaching adsorption saturation at higher concentration. This phenomenon of segmented detection sensitivity is also very common in literatures $[56,57]$. With $3 \sigma$ method (signal to noise ratio of $3(\mathrm{~S} / \mathrm{N}=3)$ ) defined by IUPAC [58], the limit of detection (LOD) is $0.093 \mu \mathrm{M}$, which is below than the maximum permissible limit of NB in drinking water guided by United States environmental protection agency $(0.138 \mu \mathrm{M})$. The sensitivity of $\mathrm{Ni} / \mathrm{Fe}-\mathrm{LDH}$ toward NB is also investigated as $(6.21 \pm 0.35),(3.85 \pm$ $0.17),(1.98 \pm 0.06) \mu \mathrm{A} \mu \mathrm{M} \mathrm{cm}{ }^{-2}$ in different concentration range. The $\mathrm{LOD}$ of Ni/Fe-LDH is further calculated to be $0.327 \mu \mathrm{M}$. Although the sensitivity of $\mathrm{Ni} / \mathrm{Fe}-\mathrm{LDH}$ is relatively low over all concentration range compared to $\mathrm{Ni} / \mathrm{Fe}(150 \mathrm{mg}$ SDS)-LDH, it is very advantageous in contrast to those electrodes reported in other articles (Table 1), indicating the catalysis and adsorption of Ni/Fe-LDH towards NB. It can conclude that compared with $\mathrm{Ni} / \mathrm{Fe}-\mathrm{LDH}$ GCE, the electrochemical performance of $\mathrm{Ni} / \mathrm{Fe}(150 \mathrm{mg}$ SDS)-LDH GCE has been greatly improved. Otherwise, compared with the previously reported sensors based on other nanomaterials (Table 1), the analytical performance of $\mathrm{Ni} / \mathrm{Fe}(150 \mathrm{mg}$ SDS)-LDH GCE is considerable, which can used for sensitive analysis of NB. This can attribute to the addition of SDS and its enhancement of adsorption to NB, suggesting that the combination of adsorption and catalysis is very valuable for the detection of organic pollutions. 

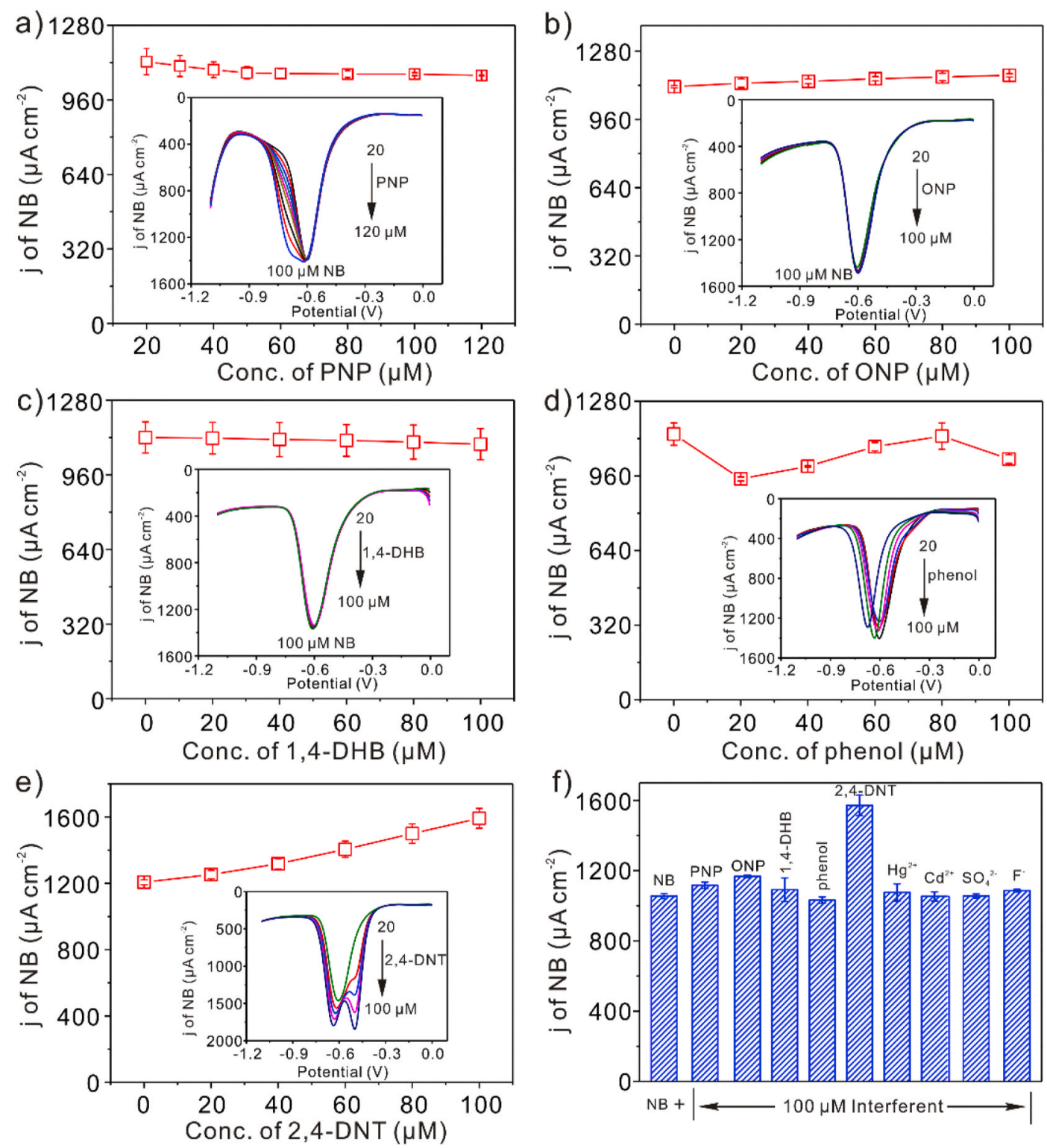

Fig. 8. Interference studies of a) p-nitrophenol (PNP), b) o-nitrophenol (ONP), c) 1,4-dihydroxybenzene (1,4-DHB), d) phenol and e) 2,4-dinitrotoluene (2,4-DNT) toward $100 \mu \mathrm{M} \mathrm{NB}$ on Ni/Fe(150 mg SDS)-LDH GCE. f) Current change of $100 \mu \mathrm{M} \mathrm{NB}$ at presence of $100 \mu \mathrm{M} \mathrm{PNP}, \mathrm{ONP}, 1,4-\mathrm{DHB}, \mathrm{phenol}, 2,4-\mathrm{DNT}, \mathrm{Hg}^{2+}, \mathrm{Cd}^{2+}, \mathrm{SO}_{4}^{2-}$ and $\mathrm{F}^{-}$, respectively.

\subsection{Adsorption behavior of $\mathrm{Ni} / \mathrm{Fe}(\mathrm{SDS})-\mathrm{LDH}$}

In order to study the difference in $\mathrm{NB}$ adsorption on $\mathrm{Ni} / \mathrm{Fe}-\mathrm{LDH}$ and $\mathrm{Ni} / \mathrm{Fe}(150 \mathrm{mg}$ SDS)-LDH, we investigated their FTIR spectra after uptake with NB (Fig. 6). The vibration peak at $1521 \mathrm{~cm}^{-1}$, attributed to benzene, clearly proves that NB is adsorbed on both LDHs. However, the stronger peak intensity of benzene on $\mathrm{Ni} / \mathrm{Fe}(150 \mathrm{mg}$ SDS)-LDH well demonstrates that its adsorption capacity is higher than that of $\mathrm{Ni} / \mathrm{Fe}-$ LDH, which can lead to a higher response of NB.

The various adsorption behaviors of $\mathrm{Ni} / \mathrm{Fe}(\mathrm{SDS})-\mathrm{LDH}$ (including with $0,50,100,150 \mathrm{mg}$ SDS) toward NB with different concentration (including 50,100, 200, 300 and $400 \mu \mathrm{M} \mathrm{NB}$ ) have been detailly explored (Fig. 7a). As presented, the order of removal efficiency of $\mathrm{Ni} / \mathrm{Fe}$ (SDS)-LDH is always $150 \mathrm{mg}>100 \mathrm{mg}>50 \mathrm{mg}>0 \mathrm{mg}$ SDS no matter the concentration of NB. This result perfectly confirms the truth of the enhancement effect of SDS on the adsorption to NB. It is also consistent with the order of DPV response current of $\mathrm{Ni} / \mathrm{Fe}(0-150 \mathrm{mg}$ SDS)-LDH in Fig. 4b, well proving the combination of adsorption and catalysis is effective. Furthermore, the removal efficiency of all Ni/Fe(SDS)-LDHs gradually decrease as the concentration of NB increases $(100-400 \mu \mathrm{M}$, Fig. 7a). This is due to that the adsorption of NB is reach maximum equilibrium at higher concentration of NB. It is also the possible reason for the different sensitivities of $\mathrm{Ni} / \mathrm{Fe}(150 \mathrm{mg}$ SDS)-LDH at various concentration range (Fig. 5d). In addition, the adsorption behaviors of $\mathrm{Ni} / \mathrm{Fe}(150 \mathrm{mg}$ SDS)-LDH to NB in diverse buffer solution and $\mathrm{pH}$ value of PBS are examined in tandem (Fig. $7 \mathrm{~b}$ and c). As expected, the $\mathrm{Ni} / \mathrm{Fe}(150$ $\mathrm{mg}$ SDS)-LDH has the biggest removal efficiency at PBS with a $\mathrm{pH}$ of 7 , completely consistent with the results obtained from electrochemical optimization condition in Fig. S7. Now, it is clear that adsorption plays key role in electrochemical analysis of $\mathrm{NB}$ on $\mathrm{Ni} / \mathrm{Fe}(150 \mathrm{mg}$ SDS)-LDH.

\subsection{Reproducibility, stability, interference and the practical application}

As for achieving the analysis of actual water samples, the reproducibility, stability, anti-interference of the fabricated electrode are evaluated for detection of NB at Ni/Fe(150 mg SDS)-LDH GCE. After consecutive 20 cycles of DPV scanning, the current of $350 \mu \mathrm{M} \mathrm{NB}$ at Ni/ Fe(150 mg SDS)-LDH GCE decreased slowly (Fig. S10a). It is because 


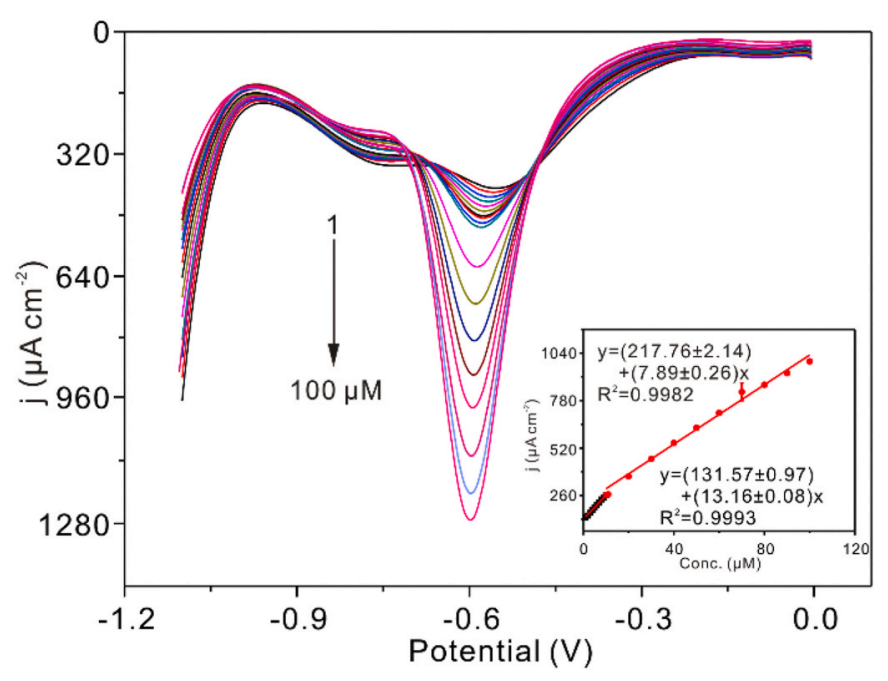

Fig. 9. The detection of NB in real sample collected from mining subsidence area on $\mathrm{Ni} / \mathrm{Fe}(150 \mathrm{mg} \mathrm{SDS})-\mathrm{LDH}$ GCE. Inset is corresponding linear calibration plot. The confidence intervals are calculated with a level of $95 \%$.

Table 2

Electrochemical detection of spiked NB in real water (underground water and tap water of Huaibei City) at the $\mathrm{Ni} / \mathrm{Fe}(150 \mathrm{mg}$ SDS)-LDH GCE ( $\mathrm{n}=3)$. HPLC method is chose as a reference method to compared with electroanalysis.

\begin{tabular}{|c|c|c|c|c|c|}
\hline & \multicolumn{2}{|c|}{ concentrations of NB } & \multirow{2}{*}{$\begin{array}{l}\text { RSD } \\
(\%)\end{array}$} & \multirow{2}{*}{$\begin{array}{l}\text { Recovery } \\
(\%)\end{array}$} & \multirow{2}{*}{$\begin{array}{l}\text { HPLC } \\
(\mu \mathrm{M})\end{array}$} \\
\hline & $\begin{array}{l}\text { Added } \\
(\mu \mathrm{M})\end{array}$ & $\begin{array}{l}\text { Found } \\
(\mu \mathrm{M})\end{array}$ & & & \\
\hline $\begin{array}{l}\text { Underground } \\
\text { water } 1\end{array}$ & 7 & $\begin{array}{l}7.31 \pm \\
0.22\end{array}$ & 3.56 & 95.75 & 7.04 \\
\hline $\begin{array}{l}\text { Underground } \\
\text { water } 2\end{array}$ & 15 & $\begin{array}{l}14.82 \pm \\
0.38\end{array}$ & 7.61 & 98.80 & 15.12 \\
\hline Tap water 1 & 7 & $\begin{array}{l}6.41 \pm \\
0.39\end{array}$ & 4.32 & 91.57 & 7.07 \\
\hline Tap water 2 & 15 & $\begin{array}{l}15.22 \pm \\
0.35\end{array}$ & 5.95 & 101.47 & 15.35 \\
\hline Tap water 3 & 20 & $\begin{array}{l}21.54 \pm \\
0.93\end{array}$ & 8.29 & 107.70 & 20.68 \\
\hline
\end{tabular}

that the adsorbed and reduced nitrobenzene cannot be released from the $\mathrm{Ni} / \mathrm{Fe}(150 \mathrm{mg} \mathrm{SDS})-\mathrm{LDH}$ in time and then inhibit the continuous accumulation of NB from solution to electrode modifier. The slight decrease could be avoided by removing the residual NB by using a fresh base solution. We compared the DPV current of $350 \mu \mathrm{M}$ NB under optimal conditions at three Ni/Fe(150 mg SDS)-LDH modified GCEs (Fig. S10b), which were prepared with same process. It is found that the peak shape and peak current of NB can be reproduced well, and a good relative standard deviation (RSD) are obtained to be $5.7 \%$. The lifetime of the sensor is further investigated. As shown in Fig. S10c, the electrochemical response toward $100 \mu \mathrm{M}$ NB on the modified electrodes, which has been respectively stored in the air for 1-3 weeks, are similar with the freshly fabricated electrode. There is no significantly change after long-time storage, well indicating the lifetime and reproducibility of the sensor is excellent. The results all indicate the excellent reproducibility and stability of $\mathrm{Ni} / \mathrm{Fe}(150 \mathrm{mg}$ SDS)-LDH.

In many cases, there will be various kinds of organic pollutants in the water environment, and they will interfere with each other. For the interference study of NB, p-nitrophenol (PNP), o-nitrophenol (ONP), 1,4-dihydroxybenzene (1,4-DHB), phenol, and 2,4-dinitrotoluene (2,4DNT) are selected as the interferences, which have very similar properties (including adsorption properties and electrochemical behaviour) with NB. When the concentration of PNP is relatively low $(0-80 \mu \mathrm{M})$, there is almost no interference to the detection of $100 \mu \mathrm{M} \mathrm{NB}$, including current and peak shape (Fig. 8a). As the concentration increases (80-120 $\mu \mathrm{M})$, although the current does not change, a new peak appears at the negative position of NB. The emergent peak is the response of PNP. The obvious changes of the peak shape and current of NB are also obtained after the addition of 2,4-DNT and phenol, especially for 2,4DNT. It is because the reduction of $-\mathrm{NO}_{2}$ on 2,4-DNT has close peak position with NB due to their similar electrochemical behavior. These results show that when there are other organic compounds, it will interfere with the detection of NB, typically for these have electrochemical activity. More works are need to solve the poor selectivity of the electrochemical sensor. However, the presence of ONP and 1,4-DHB have negligible interferences on the NB, although they have similar adsorption properties as organic matter. It is further satisfactory that the inorganic cations and anions in water have almost no negative effect on the detection of NB even with higher concentration $(0-1000 \mu \mathrm{M}$, Fig. S11).

The natural lake water samples were collected from the Nanhu Lake in Huaibei City, Anhui Province, China, and used to illustrate the accuracy of the proposed electrode in practical analysis. Nanhu Lake is a natural lake with a water area of 3.3 square kilometers formed in a coal mining subsidence area, which contains a lot of inorganic ions and biological organic matters. With simply filtering out the insoluble substances in the actual water sample, the buffer solution is obtained by mixing the $0.1 \mathrm{M}$ PBS ( $\mathrm{pH} 7.0$ ) solution with real water in a volume ratio of 9:1. As found in Fig. 9 that in actual water environment, $\mathrm{Ni} / \mathrm{Fe}(150$ mg SDS)-LDH GCE can also achieves a sensitive detection of NB. Interfering ions present in natural water will not adversely affect our detection system, and the resulting sensitivity is only slightly reduced compared to pure water environment. Otherwise, different kinds of natural aqueous systems including underground water and tap water in Huaibei City were further determined. As given in Table 2, the $\mathrm{Ni} / \mathrm{Fe}$ (150 mg SDS)-LDH GCE has a good performance to NB owning satisfied recovery and RSD in the above water environment. Furthermore, the NB spiked in real samples (including underground water and tap water) are also detected by a reference method of HPLC method to compare with electroanalytical results. As shown in Fig. S12 and Table 2, the found content of NB detected by electroanalysis is near the result of HPLC, as well as the added concentration. This result indicates the NB detection accuracy of electroanalysis on Ni/Fe(150 mg SDS)-LDH GCE is considerable and reliable. In a word, the fabricated $\mathrm{Ni} / \mathrm{Fe}(150 \mathrm{mg}$ SDS)-LDH GCE has a great potential for the practical application of actual water samples with a high accuracy and good reliability.

\section{Conclusion}

In summary, a novel chemically modified electrode for sensitive detection of the organic pollution NB has been described, based on the combination of the adsorption and catalytical properties of the $\mathrm{Ni} / \mathrm{Fe}$ (SDS)-LDH composite. Compared to the Ni/Fe-LDHs modified electrode, the proposed sensor has shown a significantly improved detection performance for NB due to the improved adsorption capability with the assistance of surface functionalization engineering of SDS. After being adsorbed, the $\mathrm{NB}$ on $\mathrm{Ni} / \mathrm{Fe}(\mathrm{SDS})$ - $\mathrm{LDH}$ can be reduced by the catalyst of $\mathrm{Ni} / \mathrm{FeO}_{6}$, offering standout performance for $\mathrm{NB}$ detection. A considerable sensitivity and LOD are achieved on Ni/Fe(SDS)-LDH even exposure with smaller specific area. The excellent electrochemical behavior indicates that the significant synergistic effect of enhanced adsorption and catalysis of $\mathrm{Ni} / \mathrm{Fe}(\mathrm{SDS})-\mathrm{LDH}$ is really effective for the sensitive detection of NB. Moreover, the practical application of the proposed sensor has been carried out for the electroanalysis of NB in the real water samples collected from mining subsidence area.

\section{Credit author statement}

Shan-Shan Li, Writing - original draft, Conceptualization, Investigation. Jin-Hui Fang, Investigation, Data curation, Validation. Li Li, 
Methodology, Formal analysis. Min Zhu, Visualization. Feng Zhang, Investigation, Visualization. Bo-Ya Zhang, Methodology, Investigation. Tian-Jia Jiang, Writing - review \& editing. Yong-Xing Zhang, Supervision, Project administration, Funding acquisition.

\section{Declaration of competing interest}

The authors declare that they have no known competing financial interests or personal relationships that could have appeared to influence the work reported in this paper.

\section{Acknowledgements}

This research is supported by the Natural Science Foundation of Anhui Province (grant No. 2008085QB70), the National Science Foundation of China (grant No. 418061119), the Key Natural Science Research Project for Colleges and Universities of Anhui Province (grant No. KJ2020A0025) and the National College Students Innovation and Entrepreneurship Training Program of China (grant No. 202010373008).

\section{Appendix A. Supplementary data}

Supplementary data to this article can be found online at https://doi. org/10.1016/j.talanta.2021.122087.

\section{References}

[1] X. Chen, X.Y. Cheng, J.J. Gooding, Detection of trace nitroaromatic isomers using indium tin oxide electrodes modified using beta-cyclodextrin and silver nanoparticles, Anal. Chem. 84 (2012) 8557-8563, https://doi.org/10.1021/ ac3014675.

[2] X. Tu, F. Gao, X. Ma, J. Zou, Y. Yu, M. Li, F. Qu, X. Huang, L. Lu, Mxene/carbon nanohorn/ $\beta$-cyclodextrin-Metal-organic frameworks as high-performance electrochemical sensing platform for sensitive detection of carbendazim pesticide, J. Hazard Mater. 396 (2020) 122776, https://doi.org/10.1016/j. jhazmat.2020.122776.

[3] D. Jemmeli, E. Marcoccio, D. Moscone, C. Dridi, F. Arduini, Highly sensitive paperbased electrochemical sensor for reagent free detection of bisphenol A, Talanta 216 (2020) 120924, https://doi.org/10.1016/j.talanta.2020.120924.

[4] H. Sohn, M.J. Sailor, D. Magde, W.C. Trogler, Detection of nitroaromatic explosives based on photoluminescent polymers containing metalloles, J. Am. Chem. Soc. 125 (2003) 3821-3830, https://doi.org/10.1021/ja021214e.

[5] F. Laghrib, S. Aghris, N. Ajermoun, A. Hrioua, M. Bakasse, S. Lahrich, M.A. El Mhammedi, Recent progress in controlling the synthesis and assembly of nanostructures: application for electrochemical determination of p-nitroaniline in water, Talanta 219 (2020) 121234, https://doi.org/10.1016/j. talanta.2020.121234.

[6] M.B. Vessely, R.P. Zitsch, Topical anesthetic-induced methemoglobinemia - a casereport and review of the literature, Otolaryng. Head Neck 108 (1993) 763-767, https://doi.org/10.1177/019459989310800623.

[7] L.J. Yan, X.J. Bo, Y.F. Zhang, L.P. Guo, Facile green synthesis of nitrogen-doped porous carbon and its use for electrocatalysis towards nitrobenzene and hydrazine, Electrochim. Acta 137 (2014) 693-699, https://doi.org/10.1016/j. electacta.2014.06.076.

[8] P. Rameshkumar, P. Viswanathan, R. Ramaraj, Silicate sol-gel stabilized silver nanoparticles for sensor applications toward mercuric ions, hydrogen peroxide and nitrobenzene, Sensor. Actuator. B Chem. 202 (2014) 1070-1077, https://doi.org/ 10.1016/j.snb.2014.06.069.

[9] X.W. Li, T. Shi, B. Li, X.C. Chen, C.W. Zhang, Z.G. Guo, Q.X. Zhang, Subtractive manufacturing of stable hierarchical micro-nano structures on AA5052 sheet with enhanced water repellence and durable corrosion resistance, Mater. Des. 183 (2019) 108152, https://doi.org/10.1016/J.Matdes.2019.108152.

[10] R. Emmanuel, C. Karuppiah, S.M. Chen, S. Palanisamy, S. Padmavathy, P. Prakash, Green synthesis of gold nanoparticles for trace level detection of a hazardous pollutant (nitrobenzene) causing Methemoglobinaemia, J. Hazard Mater. 279 (2014) 117-124, https://doi.org/10.1016/j.jhazmat.2014.06.066.

[11] Q. Wang, X.Q. Wu, L. Zhang, Designed of bifunctional Z-scheme $\mathrm{CuSnO}_{3} @ \mathrm{Cu}_{2} \mathrm{O}$ heterojunctions film for photoelectrochemical catalytic reduction and ultrasensitive sensing nitrobenzene, Chem. Eng. J. 361 (2019) 398-407, https:// doi.org/10.1016/j.cej.2018.12.079.

[12] Z.C. Hu, B.J. Deibert, J. Li, Luminescent metal-organic frameworks for chemical sensing and explosive detection, Chem. Soc. Rev. 43 (2014) 5815-5840, https:// doi.org/10.1039/c4cs00010b.

[13] K. Vellingiri, D.W. Boukhyalov, S.K. Pandey, A. Deep, K.H. Kim, Luminescent metal-organic frameworks for the detection of nitrobenzene in aqueous media,
Sensor. Actuator. B Chem. 245 (2017) 305-313, https://doi.org/10.1016/j. snb.2017.01.126.

[14] E. Holmgren, H. Carlsson, P. Goede, C. Crescenzi, Determination and characterization of organic explosives using porous graphitic carbon and liquid chromatography-atmospheric pressure chemical ionization mass spectrometry, J. Chromatogr. A 1099 (2005) 127-135, https://doi.org/10.1016/j. chroma.2005.08.088.

[15] S.P. Wang, H.J. Chen, Separation and determination of nitrobenzenes by micellar electrokinetic chromatography and high-performance liquid chromatography, J. Chromatogr. A 979 (2002) 439-446, https://doi.org/10.1016/S0021-9673(02) 01435-8.

[16] J.S. Caygill, F. Davis, S.P.J. Higson, Current trends in explosive detection techniques, Talanta 88 (2012) 14-29, https://doi.org/10.1016/j. talanta.2011.11.043.

[17] Y.T. Sang, Y.Q. Cui, Z. Li, W.N. Ye, H.L. Li, X.S. Zhao, P.Z. Guo, Electrochemical reaction of nitrobenzene and its derivatives on glassy carbon electrode modified with $\mathrm{MnFe}_{2} \mathrm{O}_{4}$ colloid nanocrystal assemblies, Sensor. Actuator. B Chem. 234 (2016) 46-52, https://doi.org/10.1016/j.snb.2016.04.154.

[18] J.Y. Dai, L. Yao, X.S. Gao, S.M. Bai, X. Chen, L. Li, J.B. Song, H.H. Yang, To achieve ultrasensitive electrochemical detection of mercury ions employing metallic 1T$\mathrm{MoS}_{2}$ nanosheets, Electrochim. Acta 355 (2020) 136800, https://doi.org/10.1016/ j.electacta.2020.136800.

[19] J. Zou, W.M. Deng, J.Z. Jiang, Arramel, X.M. He, N. Li, J.X. Fang, J.P. Hsu, Built-in electric field-assisted step-scheme heterojunction of carbon nitride-copper oxide for highly selective electrochemical detection of p-nonylphenol, Electrochim. Acta 354 (2020) 136658, https://doi.org/10.1016/j.electacta.2020.136658.

[20] Y.q. Zhong, T.j. Ning, L. Cheng, W. Xiong, G.b. Wei, F.s. Liao, G.q. Ma, N. Hong, H. f. Cui, H. Fan, An electrochemical $\mathrm{Hg}^{2+}$ sensor based on signal amplification strategy of target recycling, Talanta 223 (2021) 121709, https://doi.org/10.1016/ j.talanta.2020.121709.

[21] R. Gupta, P.K. Rastogi, V. Ganesan, D.K. Yadav, P.K. Sonkar, Gold nanoparticles decorated mesoporous silica microspheres: a proficient electrochemical sensing scaffold for hydrazine and nitrobenzene, Sensor. Actuator. B Chem. 239 (2017) 970-978, https://doi.org/10.1016/j.snb.2016.08.117.

[22] P.K. Rastogi, V. Ganesan, S. Krishnamoorthi, Palladium nanoparticles incorporated polymer-silica nanocomposite based electrochemical sensing platform for nitrobenzene detection, Electrochim. Acta 147 (2014) 442-450, https://doi.org/ 10.1016/j.electacta.2014.09.128.

[23] D.K. Yadav, V. Ganesan, P.K. Sonkar, R. Gupta, P.K. Rastogi, Electrochemical investigation of gold nanoparticles incorporated zinc based metal-organic framework for selective recognition of nitrite and nitrobenzene, Electrochim. Acta 200 (2016) 276-282, https://doi.org/10.1016/j.electacta.2016.03.092.

[24] S.A. Hira, M. Nallal, K.H. Park, Fabrication of PdAg nanoparticle infused metalorganic framework for electrochemical and solution-chemical reduction and detection of toxic 4-nitrophenol, Sensor. Actuator. B Chem. 298 (2019), 127586 https://doi.org/10.1016/j.snb.2019.126861.

[25] X.Y. Zhao, A.L. Li, X. Quan, S. Chen, H.T. Yu, S.S. Zhang, Efficient electrochemical reduction of nitrobenzene by nitrogen doped porous carbon, Chemosphere 238 (2020) 124636, https://doi.org/10.1016/j.chemosphere.2019.124636.

[26] Y.F. Zhang, X.J. Bo, A. Nsabimana, C. Luhana, G. Wang, H. Wang, M. Li, L.P. Guo, Fabrication of 2D ordered mesoporous carbon nitride and its use as electrochemical sensing platform for $\mathrm{H}_{2} \mathrm{O}_{2}$, nitrobenzene, and NADH detection, Biosens. Bioelectron. 53 (2014) 250-256, https://doi.org/10.1016/j.bios.2013.10.001.

[27] J. Chen, S. Lin, J. Yu, Quantitative effects of $\mathrm{Fe}_{3} \mathrm{O}_{4}$ nanoparticle content on $\mathrm{Li}^{+}$ adsorption and magnetic recovery performances of magnetic lithium-aluminum layered double hydroxides in ultrahigh $\mathrm{Mg} / \mathrm{Li}$ ratio brines, J. Hazard Mater. 388 (2020), 122101, https://doi.org/10.1016/j.jhazmat.2020.122101.

[28] Y. Wang, C. Xie, Z. Zhang, D. Liu, R. Chen, S. Wang, In situ exfoliated, N-doped, and edge-rich ultrathin layered double hydroxides nanosheets for oxygen evolution reaction, Adv. Funct. Mater. 28 (2018), 1703363, https://doi.org/10.1002/ adfm. 201703363.

[29] P.S. Li, M.Y. Wang, X.X. Duan, L.R. Zheng, X.P. Cheng, Y.F. Zhang, Y. Kuang, Y. P. Li, Q. Ma, Z.X. Feng, W. Liu, X.M. Sun, Boosting oxygen evolution of singleatomic ruthenium through electronic coupling with cobalt-iron layered double hydroxides, Nat. Commun. 10 (2019) 1711, https://doi.org/10.1038/s41467-01909666-0.

[30] I.K.M. Yu, A. Hanif, D.C.W. Tsang, J. Shang, Z.S. Su, H. Song, Y.S. Ok, C.S. Poon, Tuneable functionalities in layered double hydroxide catalysts for thermochemical conversion of biomass-derived glucose to fructose, Chem. Eng. J. 383 (2020) 122914, https://doi.org/10.1016/j.cej.2019.122914.

[31] X.L. Zhang, Y. Xue, J.T. Gao, C.Y. He, Y.S. Ji, Y.K. Dou, Comparison of adsorption mechanisms for cadmium removal by modified zeolites and sands coated with $\mathrm{Zn}$ layered double hydroxides, Chem. Eng. J. 380 (2020) 122578, https://doi.org/ 10.1016/j.cej.2019.122578.

[32] Z. Li, F. Han, C. Li, X. Jiao, D. Chen, Multi-anion intercalated layered double hydroxide nanosheet-assembled hollow nanoprisms with improved pseudocapacitive and electrocatalytic properties, Chem. Asian J. 13 (2018) 1129-1137, https://doi.org/10.1002/asia.201800092.

[33] W. Liu, J. Bao, M. Guan, Y. Zhao, J. Lian, J. Qiu, L. Xu, Y. Huang, J. Qian, H. Li, Nickel-cobalt-layered double hydroxide nanosheet arrays on $\mathrm{Ni}$ foam as a bifunctional electrocatalyst for overall water splitting, Dalton Trans. 46 (2017) 8372-8376, https://doi.org/10.1039/c7dt00906b.

[34] L. Yu, J.F. Yang, B.Y. Guan, Y. Lu, X.W. Lou, Hierarchical hollow nanoprisms based on ultrathin Ni-Fe layered double hydroxide nanosheets with enhanced electrocatalytic activity towards oxygen evolution, Angew. Chem. Int. Ed. 57 (2018) 172-176, https://doi.org/10.1002/anie.201710877. 
[35] K. Yan, T. Lafleur, J.J. Chai, C. Jarvis, Facile synthesis of thin NiFe-layered double hydroxides nanosheets efficient for oxygen evolution, Electrochem, Commun Now. 62 (2016) 24-28, https://doi.org/10.1016/j.elecom.2015.11.004.

[36] P.S. Li, X.X. Duan, Y. Kuang, Y.P. Li, G.X. Zhang, W. Liu, X.M. Sun, Tuning electronic structure of NiFe layered double hydroxides with vanadium doping toward high efficient electrocatalytic water oxidation, Adv. Energy. Mater. 8 (2018) 1703341, https://doi.org/10.1002/aenm.201703341.

[37] Y. Pei, Y. Ge, H. Chu, W. Smith, P. Dong, P.M. Ajayan, M. Ye, J. Shen, Controlled synthesis of 3D porous structured cobalt-iron based nanosheets by electrodeposition as asymmetric electrodes for ultra-efficient water splitting, Appl. Catal. B Environ. 244 (2019) 583-593, https://doi.org/10.1016/j. apcatb.2018.11.091.

[38] Y. Wang, Y. Zhang, Z. Liu, C. Xie, S. Feng, D. Liu, M. Shao, S. Wang, Layered double hydroxide nanosheets with multiple vacancies obtained by dry exfoliation as highly efficient oxygen evolution electrocatalysts, Angew. Chem. Int. Ed. 56 (2017) 5867-5871, https://doi.org/10.1002/anie.201701477.

[39] R. Liu, Y. Wang, D. Liu, Y. Zou, S. Wang, Water-plasma-enabled exfoliation of ultrathin layered double hydroxide nanosheets with multivacancies for water oxidation, Adv. Mater. 29 (2017) 1701546, https://doi.org/10.1002/ adma.201701546.

[40] X. Long, Z.L. Wang, S. Xiao, Y.M. An, S.H. Yang, Transition metal based layered double hydroxides tailored for energy conversion and storage, Mater. Today 19 (2016) 213-226, https://doi.org/10.1016/j.mattod.2015.10.006.

[41] K. Nejati, K. Asadpour-Zeynali, Electrochemical synthesis of nickel-iron layered double hydroxide: application as a novel modified electrode in electrocatalytic reduction of metronidazole, Mat. Sci. Eng. C-Mater. 35 (2014) 179-184, https:// doi.org/10.1016/j.msec.2013.11.003.

[42] K. Grover, S. Komarneni, H. Katsuki, Uptake of arsenite by synthetic layered double hydroxides, Water Res. 43 (2009) 3884-3890, https://doi.org/10.1016/j. watres.2009.06.003.

[43] Y. Dai, G. Qian, Y. Cao, Y. Chi, Y. Xu, J. Zhou, Q. Liu, Z.P. Xu, S. Qiao, Effective removal and fixation of $\mathrm{Cr}(\mathrm{VI})$ from aqueous solution with Friedel's salt, J. Hazard Mater. 170 (2009) 1086-1092, https://doi.org/10.1016/j. jhazmat.2009.05.070.

[44] P. Zhang, G.R. Qian, Z.P. Xu, H.S. Shi, X.X. Ruan, J. Yang, R.L. Frost, Effective adsorption of sodium dodecylsulfate (SDS) by hydrocalumite (CaAl-LDH-Cl) induced by self-dissolution and re-precipitation mechanism, J. Colloid Interface Sci. 367 (2012) 264-271, https://doi.org/10.1016/j.jcis.2011.10.036.

[45] X.X. Ruan, P. Sun, X.X. Ouyang, G.R. Qian, Characteristics and mechanisms of sorption of organic contaminants onto sodium dodecyl sulfate modified Ca-Al layered double hydroxides, Chin. Sci. Bull. 56 (2011) 3431-3436, https://doi.org/ 10.1007/s11434-011-4762-y.

[46] Y.W. You, H.T. Zhao, G.F. Vance, Surfactant-enhanced adsorption of organic compounds by layered double hydroxides, Colloid. Surface. 205 (2002) 161-172, https://doi.org/10.1016/S0927-7757(01)01137-2.

[47] B. Thirumalraj, S. Palanisamy, S.M. Chen, K. Thangavelu, P. Periakaruppan, X. H. Liu, A simple electrochemical platform for detection of nitrobenzene in water samples using an alumina polished glassy carbon electrode, J. Colloid Interface Sci. 475 (2016) 154-160, https://doi.org/10.1016/j.jcis.2016.04.042.

[48] L.M. Cao, J.W. Wang, D.C. Zhong, T.B. Lu, Template-directed synthesis of sulphur doped NiCoFe layered double hydroxide porous nanosheets with enhanced electrocatalytic activity for the oxygen evolution reaction, J. Mater. Chem. 6 (2018) 3224-3230, https://doi.org/10.1039/c7ta09734d.

[49] L. Wang, Z.H. Dong, Z.G. Wang, F.X. Zhang, J. Jin, Layered $\alpha-\mathrm{Co}(\mathrm{OH})_{2}$ nanocones as electrode materials for pseudocapacitors: understanding the effect of interlayer space on electrochemical activity, Adv. Funct. Mater. 23 (2013) 2758-2764, https://doi.org/10.1002/adfm.201202786.

[50] J. Zhu, P. Yuan, H. He, R. Frost, Q. Tao, W. Shen, T. Bostrom, In situ synthesis of surfactant/silane-modified hydrotalcites, J. Colloid Interface Sci. 319 (2008) 498-504, https://doi.org/10.1016/j.jcis.2007.11.037.

[51] E.P. Rebitski, G.P. Souza, S.A.A. Santana, S.B.C. Pergher, A.C.S. Alcantara, Bionanocomposites based on cationic and anionic layered clays as controlled release devices of amoxicillin, Appl. Clay Sci. 173 (2019) 35-45, https://doi.org/ 10.1016/j.clay.2019.02.024

[52] P. Zhang, S.D. Ouyang, P. Li, Y. Huang, R.L. Frost, Enhanced removal of ionic dyes by hierarchical organic three-dimensional layered double hydroxide prepared via soft-template synthesis with mechanism study, Chem. Eng. J. 360 (2019) 1137-1149, https://doi.org/10.1016/j.cej.2018.10.179.

[53] H. Chen, G.R. Qian, X.X. Ruan, R.L. Frost, Removal process of nickel(II) by using dodecyl sulfate intercalated calcium aluminum layered double hydroxide, Appl. Clay Sci. 132 (2016) 419-424, https://doi.org/10.1016/j.clay.2016.07.008.

[54] L. Deng, H.X. Zeng, Z. Shi, W. Zhang, J.M. Luo, Sodium dodecyl sulfate intercalated and acrylamide anchored layered double hydroxides: a multifunctional adsorbent for highly efficient removal of Congo red, J. Colloid Interface Sci. 521 (2018) 172-182, https://doi.org/10.1016/j.jcis.2018.03.040.

[55] X.Y. Duan, F. Xu, Y.N. Wang, Y.W. Chen, L.M. Chang, Fabrication of a hydrophobic SDBS- $\mathrm{PbO}_{2}$ anode for electrochemical degradation of nitrobenzene in aqueous solution, Electrochim. Acta 282 (2018) 662-671, https://doi.org/10.1016/j. electacta.2018.06.098.

[56] J. Wei, S.S. Li, Z. Guo, X. Chen, J.H. Liu, X.J. Huang, Adsorbent assisted in situ electrocatalysis: an ultra-sensitive detection of $\mathrm{As}(\mathrm{III})$ in water at $\mathrm{Fe}_{3} \mathrm{O}_{4}$ nanosphere densely decorated with Au nanoparticles, Anal. Chem. 88 (2016) 1154-1161, https://doi.org/10.1021/acs.analchem.5b02947.

[57] J.J. Zhang, S.Q. Cui, Y.P. Ding, X.X. Yang, K. Guo, J.T. Zhao, Two-dimensional mesoporous $\mathrm{ZnCo}_{2} \mathrm{O}_{4}$ nanosheets as a novel electrocatalyst for detection of onitrophenol and p-nitrophenol, Biosens. Bioelectron. 112 (2018) 177-185, https:// doi.org/10.1016/j.bios.2018.03.021.

[58] J. Mocak, A.M. Bond, S. Mitchell, G. Scollary, A statistical overview of standard (IUPAC and ACS) and new procedures for determining the limits of detection and quantification: application to voltammetric and stripping techniques, Pure Appl. Chem. 69 (1997) 297-328, https://doi.org/10.1351/pac199769020297.

[59] Y.F. Zhang, X.J. Bo, A. Nsabimana, C. Han, M. Li, L.P. Guo, Electrocatalytically active cobalt-based metal-organic framework with incorporated macroporous carbon composite for electrochemical applications, J. Mater. Chem. 3 (2015) 732-738, https://doi.org/10.1039/c4ta04411h.

[60] W.S. Bai, Q.L. Sheng, X.Y. Ma, J.B. Zheng, Synthesis of silver nanoparticles based on hydrophobic interface regulation and its application of electrochemical catalysis, ACS Sustain. Chem. Eng. 3 (2015) 1600-1609, https://doi.org/10.1021/ acssuschemeng.5b00297.

[61] V.M. Kariuki, S.A. Fasih-Ahmad, F.J. Osonga, O.A. Sadik, An electrochemical sensor for nitrobenzene using pi-conjugated polymer-embedded nanosilver, Analyst 141 (2016) 2259-2269, https://doi.org/10.1039/c6an00029k. 